\title{
Educational Mismatch and Income Inequality in Developing Countries
}

Hao $\operatorname{Tan}^{1 *}$

Xin Wang ${ }^{2}$

\begin{abstract}
This study aims to evaluate the influence of educational mismatch on income inequality in developing countries. The research is conducted using secondary data from ten developing countries over a twenty-year period (2001-2020). Statistical analysis is performed on the dataset using Stata, where the main variable representing income inequality is the GINI coefficient, and educational mismatch is assessed using educational attainment, educational attainment of females, and educational expenditure. The fixed effect and robust standard error techniques are applied to address the association among the variables. The study's findings reveal that educational attainment and educational expenditure have a positive influence on the GINI coefficient, indicating that the two factors contribute to an educational mismatch in the developing country. On the other hand, the findings also reveal that the educational attainment offemales has a negative effect on the GINI coefficient, indicating that a high level of educational attainment among females can help to improve the income equality of developing countries. The implications of the study are particularly relevant to the policymakers and governments of developing countries. They should take steps to increase the level of education among females to contribute to increased income equality levels in their country.
\end{abstract}

Funding: This study received no specific financial support.

Competing Interests: The authors declare that they have no competing interests.

\section{Introduction}

Educational mismatch can be described as the situation in which a worker's skill set is not suitable for a certain job description. Education plays a critical role in generating employment within a country. The basic purpose of education is to make a person literate and equip them with different skills to enable them to earn a living. However, problems arise when the provided education cannot ensure that a person finds a suitable job. This phenomenon is educational mismatch (Bender \& Roche, 2013), the incompatibility of education with the skills required for a particular job (Korpi \& Tåhlin, 2009). Growing economies, for instance, usually focus on vocational training to provide the necessary skills to people who will go on to form a major part of their labor force. However, in many countries, there is less focus on skills. Rather, education has become a trend everyone participates in for the sake of it. Nonetheless, educational mismatch has been shown to lead to income inequality, especially in developing countries (Budría \& Moro-Egido, 2008). Since this phenomenon can be observed in such regions, education must be optimized to increase income. This study aims to assess educational mismatch and income equality and their connection with the education frameworks utilized by developing countries.

The problem arises when the required skills for a particular job are misunderstood. For instance, if marketers need behavioral and cognitive skills to perform marketing-based jobs, the educational institutions are not ingraining such skills. Educational mismatch often leads to income inequality (Rohrbach-Schmidt \& Tiemann, 2016) when foreign graduates are preferred to local ones (Sweetman, McDonald, \& Hawthorne, 2015). However, there is a lack of research on the educational mismatch perspectives that lead to unemployment pitfalls. In this context, the present study tries to comprehensively delineate the correlation between educational mismatch and income inequality. Though different studies have been conducted in similar domains, less literature exists on educational mismatch. One commonly observed phenomenon is that education increases 
employment and productivity and leads to economic growth, but it has also been shown to lead to labor market gaps and income inequality (Santos, 2012).

Before studying educational mismatch and income inequality in developing countries, the history and evolution of education must be taken into account. Once, education was limited to the rich and the upper classes. During the era of Plato and Socrates, education was confined to royalty and their associates (Williams, 2010). However, during the 19th century, education became widespread, and many academic institutions began to open (Andersson \& Berger, 2016). Women were also increasingly being enrolled in educational institutions. At the same time, the colonization of different regions around the world had also been firmly established. The French, British, and Portuguese had several colonies in South Asia and Africa. In South Asia, the British established an early English-based education system that served to further the English-conscious culture within the region. In contrast, Nigeria was one of the French colonies in Africa. When colonization ended, Nigeria continued to use French as a medium of education in its schools (Olagbaju, 2014). Possibly because the mother tongue was completely ignored and French was made the lingua franca in the country, Nigeria currently has one of the lowest literacy rates in the world. In the present day, educational materials are mostly written and imported in English. However, several countries have retained their national languages as a part of their educational system. From a global perspective, key educational skills usually include stress management, language, communication, and the curiosity to learn (Bourn, 2018). When assessing the educational standards in developing countries, these key skills are usually missing. For this reason, educational mismatch and income inequality are highly correlated in developing countries.

Over the last thirty to forty years, most low to middle-income and developing countries have invested heavily in their educational systems (Sam, 2018). Moreover, they are making incredible strides in terms of the rate of literacy and the extent of the curriculum offered, while significantly improving the rate of enrolment in primary, secondary, and tertiary levels. Considering the tertiary level, in particular, university graduates tend to struggle more to find jobs that are consistent with their level of education and are related to the field of their degree. These are vertical and horizontal mismatches (Chua \& Chun, 2016). In theory, if one assumes that job seekers have limited access to information on possible job opportunities, they face the choice between accepting their first job offer, which may not match their degree, and being unemployed while waiting for a superior and more suitable job (Maier, 2015). In contrast, if there are many, diverse workers, and job opportunities are limited, some of the workers may fail to find a well-matched position and be unemployed for an extensive period.

This paper examines the impact of educational mismatch on income inequality in developing countries. In doing so, the research attempts to understand the theoretical concepts of educational mismatch and income equality, identify the specific factors of educational mismatch that influence income inequality in developing countries, and determine the impact of educational mismatch on income inequality in developing countries. The research will help education and market professionals to bridge the gap between required and imparted skills. It will also highlight certain perspectives relating to education mismatches, such as the issues of skill-based education and experiential learning (Gomathi \& Rajamani, 2018). On the other hand, vocational training will also be examined to ascertain whether it influences employment within a country or not. Finally, income inequality will be analyzed by means of literacy gaps in developing countries.

\section{Literature Review}

The enrolment rate in educational institutions in developing countries is rapidly increasing over time. Yet, there is a greater concern, based on the concept of educational mismatch. An educational mismatch refers to a situation in which an employee's educational qualifications fail to match the qualifications needed to perform the job for which they are hired. A mismatch can also be vertical, meaning that the level of the employee's qualifications is not what the occupation requires (Khan, 2019). Educational mismatch often results in unemployment and thus leads to certain social crises. Usually, an individual expects that their education will allow them to get a suitable job. However, the practical market realities can be very different from the expectations. In this context, the gap between required skills and empathy skills widens further. As a result, students are unable to cope with the issues. The rote learning and cramming culture also discourages student creativity. These systems usually promote stagnant minds. Practically, when students are exposed to real market scenarios and challenges outside their educational institutions, the rote learning culture often culminates in the failure of many students. In contrast, academic institutions that promote creativity through conceptual learning and experiential learning find that their students are more likely to secure jobs in a competitive market (Schmidt, Resnick, \& Ito, 2016). Hence, it can be contended that income inequality is further exaggerated by the segregated educational system. The divisions are stratified at the level of skills across educational levels. The elite schools have updated curricula, and the skills they teach are compatible with the market requirements (Kenway \& Fahey, 2014). The middle- and low-income educational institutions generally focus on rote learning, which further exaggerates the income equality gap in developing countries (Nag, Snowling, \& Asfaha, 2016). The classoriented education system thus often exacerbates income inequality in developing countries. Various reasons for the mismatch in education can be identified, particularly in developing countries, including communication, deliberate thinking, abstract reasoning, and research skills. The economic role of human capital-specific education has long been recognized by economists and policymakers. In the case of developing countries, two 
concurrent phenomena are observed. One is the relatively poor educational uptake that tends to result in the under-education of the masses and the over-education of the elite. In truth, the under-education of the underprivileged is a significant problem in the developing labor markets.

Mismatches between the skills that workers tend to possess and the requirements of jobs tend to have negative consequences in terms of productivity levels and social welfare (Battu \& Bender, 2020). For the workers, mismatches can restrict their career progression and the skills developed on the job while negatively affecting their earnings (Battu \& Bender, 2020). As mismatches have significant consequences, it is important to identify the factors that affect match quality to determine the types of policy interventions that can help improve the matching process. Wage inequality, in terms of the level and dispersal of wages, tends to arise between groups of matched and mismatched workers. Regarding the theoretical literature on the aspects of job search and matching, in developing countries, the skill mismatch tends to reflect the presence of resistance. A measure of the general skill mismatch can be defined as the degree to which workers are mismatched with regards to the requirements of their jobs, either due to required training in the occupation or alternatively the formal level of education attained in the relevant field of study (Lindgren, Lundman, \& Graneheim, 2020).

The duration of unemployment tends to increase with the problems related to mismatches. Thus, there is evidence for the negative effects of mismatches on wages. Certainly, working in a mismatched job does not allow workers to explore and expand on their respective skills (Khan, 2019). Apart from this, wages tend to reduce with the level of mismatch that a person experiences. Two theoretical approaches to the problem are in opposition. First, a worker's level of productivity depends upon both the attributes of the job and personal characteristics (Chua \& Chun, 2016). Therefore, over-educated employees are quite productive compared to their counterparts in similar jobs suitable for attaining economic growth. Human capital theory was the first formalized theory to describe the concept of education mismatch (EERA, 2016). It states that the skills acquired through education tend to represent an investment in human capital, leading to greater productivity and returns for education. It even suggests that wages can be determined primarily through the supply of human capital. The competition model of jobs provides a completely different perspective than human capital theory (EERA, 2016). Wages are determined by the characteristics of the job rather than the level of education attained by the workers. Therefore, in the job competition model, earnings are affected by demand. The mismatch (specifically that of over-education) arises when workers who are educated beyond the job requirements stay in the employment queue or displace less educated people (Ordine \& Rose, 2017).

The impact of education on jobs should never be ignored (Mukhtyar, Saleem, \& Iqbal, 202 1; Watts, Bowles, Fisher, \& Li, 2021). An educational mismatch occurs when the skills of the worker do not match the requirements of the job. This mismatch leads to income inequality. "The right person for the right job" is the basis of human resources, and it supports the concept of congruence between income and education (Zhu et al., 2018). Education helps firms to draft employee categories according to their knowledge and skills, and it is education and skills that result in differences in employee remuneration. A highly skilled person cannot be given the same remuneration as a low-educated and low-skilled employee. That would lead to employee demotivation and social discrimination. In this context, Tang and Wang (2021) explored the nexus between income and educational mismatch. They tested data from 1990 to 2000, and the results revealed a positive association between education and income inequality. The study suggested implementing educational policies to help eliminate income inequality. Often, the firms that fail to implement the proper human resources philosophy fail to differentiate between skilled and unskilled employees. This leads to demoralization, which in turn results in increased employee turnover. Similarly, Lu and Li (2021) also investigated the nexus between education and income inequality and found that income and education mismatch significantly impact each other.

Employees are considered the blood of a company. Usually, high wages in a firm are due to the employee's high level of education. This not only creates a distinction between skilled and unskilled workers on the basis of education but also encourages less-educated employees to focus on their education in order to enhance their skills. Mahmud and Akita (2018) also investigated the impact of education mismatch on income inequality in Bangladesh. Based on data from 2005 to 2010, the results revealed an association between income and education mismatch. Another aspect is whether income inequality also leads to education mismatch. This scenario can be viewed from the point of view of a business. When a company does not know which employees are capable of performing efficient work, giving all employees an average salary appears to be a viable alternative. This is the simplest way to discourage good employees while rewarding poor ones. To tackle this challenge, it is advisable to use educational attainment to assess the workforce's capacity. In this context, Arshed, Hassan, and Aziz (2020) investigated whether income inequality leads to educational mismatch. Their results revealed that inequality in income restricts people from attaining the same level of education across all levels of society. A decent income encourages employees to get themselves as well as their families a high level of education. In conclusion, the literature agrees that educational mismatch leads to income inequality.

\section{Methodology}

In this study, the researcher aimed to extend the data on educational mismatches in the context of developing countries. The equation for the study is calculated as:

$$
G I N I_{i t}=\beta_{0}+\beta_{1} E E_{i t}+\beta_{3} E A F_{i t}+\beta_{4} E A_{i t}+u_{i t}
$$


Where:

GINI = GINI Index

$\mathrm{i}=$ Country.

$t=$ Time Period.

$\mathrm{EE}=$ Education Expenditure.

$\mathrm{EAF}=$ Education Attainment Female.

$\mathrm{EA}=$ Education Attainment.

The discussion will be based upon all forms and dimensions of mismatch, whether vertical or horizontal, single or double. The research is quantitative and incorporates secondary data to structure the research. A quantitative research design has been adopted because the variables of this study are quantifiable and measurable through quantitative testing and statistical analysis. Therefore, the research philosophy that underlies this research is positivism, and a deductive research approach is employed (Maier, 2015). This philosophy and approach help in the quantification of the variables and the collection of numerical data that can be transformed into statistical equations. As this research intends to analyze educational mismatch and income inequality in developing countries, and these are quantifiable and numerical variables, the adoption of these approaches is suitable (Chua \& Chun, 2016).

\subsection{Data Collection and Sources}

Secondary sources are used to collect the time-series data, such as the World Development Indicators of developing countries from the World Bank and Central Bank. The collected data covers a twenty-year period from 2001 to 2020. Moreover, secondary sources are collected from Google Scholar, Emerald, and Wiley. Secondary studies are collected to compare and contrast this study's findings with prior studies so that results can be validated, authenticated, and generalized.

\subsection{Variables and Measurements}

The study evaluates the impact of educational mismatch on income inequality in developing countries. Income inequality, in this case, is the dependent variable, and the educational mismatch is the independent variable. Income inequality is measured using the GINI index, whereas different variables are used to indicate the education mismatch in developing countries. Table 1 lists the variables of the study and how they are measured using different proxies, along with the descriptions of these proxies.

Table 1. Measurement of the variables.

\begin{tabular}{l|l|l}
\hline Variables & \multicolumn{1}{|c}{ Measurement/Proxies } & \multicolumn{1}{c}{ Description } \\
\hline Income inequality & GINI Index & $\begin{array}{l}\text { The GINI index measures the distribution of income } \\
\text { within the population. A higher GINI index reflects } \\
\text { greater inequality. }\end{array}$ \\
\hline \multirow{3}{*}{ Education mismatch } & Education Expenditure & $\begin{array}{l}\text { The government's total expenditure on the education } \\
\text { sector. }\end{array}$ \\
\cline { 2 - 3 } & $\begin{array}{l}\text { Education Attainment } \\
\text { (Female) }\end{array}$ & $\begin{array}{l}\text { The education attainment rate of females in a particular } \\
\text { country. }\end{array}$ \\
\cline { 2 - 3 } & Education Attainment & $\begin{array}{l}\text { The percentage of the population that has completed } \\
\text { their education. }\end{array}$ \\
\hline
\end{tabular}

\subsection{Data Analysis Techniques}

The data analysis technique used in this study is statistical panel data analysis, as the study is conducted using the quantitative secondary data of different cross-sections over different periods, which indicates the use of panel data. The statistical analysis of the panel data has been conducted using STATA software. The data is first analyzed using descriptive statistics, summarizing the data based on means and standard deviation. This shows the average value and the variation in the data set. Next, correlation analysis is carried out to indicate the strength of the relationship between the variables. Pairwise correlation is conducted using the Pearson correlation coefficient, which better evaluates the relationship between the variables. Furthermore, the panel data regression is estimated to indicate the influence of income inequality on the education mismatch. The panel data is estimated in different steps.

The current study has also checked the multicollinearity among the constructs using the variance inflation factor (VIF). The rule of thumb of the VIF is that the values should be lower than five, which indicates no multicollinearity among the variables. The equations are given below:

$$
\begin{aligned}
& \mathrm{R}^{2} \mathrm{Y} \\
& j=R_{Y}^{2}, R_{X 1}^{2}, R_{X 2}^{2}, R_{X 3}^{2}, R_{X 4}^{2}, R_{X 5}^{2} \\
& \text { Tolerance }=1-R_{j}^{2} \quad V I F=\frac{1}{\text { Tolerance }}
\end{aligned}
$$


First, the panel regression is estimated for the random effect model, and the estimates are stored for further diagnostics. Next, the fixed-effect model (FEM) is estimated, and the estimates are stored for diagnostics. The Hausman specification test is further evaluated to indicate the applicability of the random or fixed-effect model for the regression analysis. The null hypothesis of the panel data indicates that the random effect model is applicable, whereas the alternative hypothesis indicates the suitability of FEM. The equation for the Hausman test is given below.

$$
H=\left(b_{1}-b_{0}\right)\left(\operatorname{Var}\left(b_{0}\right)-\operatorname{Var}\left(b_{1}\right)\right)\left(b_{1}-b_{0}\right)
$$

Diagnostic tests are further conducted to check whether the regression assumptions are accomplished. The above models show no violations of any assumptions, such as heteroscedasticity or serial autocorrelation. The heteroscedasticity is tested using the modified Wald test, where the null hypothesis indicates the presence of homoscedasticity and the alternative hypothesis the presence of heteroscedasticity. Furthermore, the serial autocorrelation is tested using the Wooldridge test for autocorrelation. Here, the null hypothesis indicates that there is no first-order autocorrelation. Having resolved these issues and calculated the Hausman test result, FEM is estimated. This is the regression technique used to resolve the regression model issues of autocorrelation and heteroscedasticity. Therefore, to identify such problems in the preliminary testing, the researcher has opted for the FEM. The FEM is fixed for heteroscedasticity and autocorrelation to better estimate the outcomes.

However, if autocorrelation and heteroscedasticity are found in the data, the FEM technique will further address the problems. The FEM equation estimates the panel data regression within the different assumptions over the cross-sectional structure correlation of errors. The estimators are attractive when the cross-section is relatively small compared to the time-series dimension. The FEM equation in the panel data has two indices: $\mathrm{t}$ and i. The models estimated using the observations are considered arbitrarily correlated and heteroskedastic across j, and the index does not possess inherent ordering. The researchers can either be agnostic regarding the error dependence structure and estimate the OLS regression following the robust variance or develop the additional related restrictive assumptions that make the FEM best linear unbiased estimator and proceed with the FEM estimation for the non-robust variances. Wooldridge (2010) has provided the formulae for FEM with the robust variance matrix. The interpretation is that the panel data have random sampling. I refer here to the cross-sections, and $\mathrm{T}$ refers to the time series periods in the panel data. Therefore, the equation of the FEM estimator is as follows:

$$
G I N I_{i t}=\beta_{0}+\beta_{1} E E_{i t}+\beta_{3} E A F_{i t}+\beta_{4} E A_{i t}+u_{i t}
$$

Finally, a robust standard error is also run to test the association among variables. In addition, it is used due to its characteristic of adjustment to the model's "heterogeneity issues" that generally exist. Moreover, Chin, Ioannidis, Tanner, and Cripps (2021) exposed that "non-robust standard errors" estimates can be misleading, and in this case, "robust standard errors" perform well. The equation is as follows:

$$
G I N I_{i t}=\beta_{1} E E_{i t}+\beta_{2} E A F_{i t}+\beta_{3} E A_{i t}+\varepsilon_{i t}
$$

The Granger causality test is also run to explore the nexus among the constructs. This test has provided the "bilateral, unilateral, and no relationships" among the studied variables. The equations related to the Granger causality test are as follows:

$$
\begin{aligned}
& \mathrm{Y}_{\mathrm{t}}=\beta_{0}+\sum_{\mathrm{j}=1} \beta_{1 \mathrm{j}} \mathrm{Y}_{\mathrm{t}-1}+\sum_{\mathrm{h}=1} \beta_{2 \mathrm{~h}} \mathrm{Y}_{\mathrm{t}-\mathrm{p}}+\varepsilon_{\mathrm{t}} \\
& \mathrm{X}_{\mathrm{t}}=\alpha_{0}+\sum_{\mathrm{s}=1} \alpha_{1 \mathrm{~s}} \mathrm{Y}_{\mathrm{t}-\mathrm{s}}+\sum_{\mathrm{t}=1} \alpha_{2 \mathrm{t}} \mathrm{X}_{\mathrm{t}-\mathrm{m}}+\varepsilon_{\mathrm{t}}
\end{aligned}
$$

\section{Findings of the Study}

This section provides the study results, including the descriptive statistics, correlation matrix, variance inflation factor (VIF) for multicollinearity, Hausman test to select the suitable model, FEM and robust standard error model to check relationships, and Granger causality test.

\subsection{Correlation Analysis}

Descriptive statistics are a simple statistical technique that summarizes the raw data into a meaningful and interpretable form. Several aspects are examined using descriptive statistics, including the central tendency, dispersion, and range of the dataset (Kaur, Stoltzfus, \& Yellapu, 2018; Pyzdek, 2021). Table 2 presents the descriptive statistics of the four main variables involved in the research: GINI, educational expenditure, educational attainment of females, and overall educational attainment. The total number of observations identified for each variable is 200 , reflecting the data of the developing countries. The total number of countries examined in the study is 10 , and each country was examined from 2001 till 2020, which represents a twentyyear period. The mean value of GINI is computed as $39.22 \%$, indicating the economic inequality in the population due to the distribution of wealth. The mean value demonstrates that there is a moderate level of income 
inequality in developing countries. The standard deviation is computed as 6.75 , which indicates that income inequality can increase or decline by $6.75 \%$. The minimum value of GINI is $27 \%$, whereas the maximum level of GINI is $54.90 \%$. Regarding the educational expenditure, the mean value is computed as 30.4 billion, which indicates an average level of expenditure on education on the part of the developing countries. The standard deviation is computed as 33 billion, which suggests an incline or decline in the educational expenditure of 33 billion.

In respect to educational attainment among females, the average proportion of females that has received an education in developing countries is computed as $15.65 \%$. The standard deviation is computed as $4.94 \%$, which indicates that the educational attainment among females can either incline or decline by $4.94 \%$. The minimum level of educational attainment among females is $3.06 \%$, and the maximum is $34.38 \%$. In general, the educational attainment among females is thus very low. Lastly, the average overall educational attainment among the developing countries is $22.64 \%$, with a standard deviation of $11.12 \%$.

\begin{tabular}{l|c|c|c|c|c} 
Table 2. Descriptive statistics. \\
\hline Variable & Obs. & Mean & S.D. & Min. & Max. \\
\hline GINI & 200 & 39.22 & 6.75 & 27.00 & 54.90 \\
\hline Education expenditure (Millions) & 200 & 30.400 & 33.000 & 220 & 140.000 \\
\hline Educational attainment (Female) & 200 & 15.65 & 4.94 & 3.06 & 34.38 \\
\hline Educational attainment & 200 & 22.64 & 11.12 & 6.65 & 59.24 \\
\hline
\end{tabular}

\subsection{Correlation Analysis}

Table 3 reflects the correlation assessment, where the purpose of the technique is to examine the association among the variables. The correlation reflects the evaluation of three aspects: the significance expressed by the p-value, the level based on the symbol, and the strength as expressed through the coefficient value (Guetterman, 2019; Polozov, Popovich, \& Kraev, 2021). The main variable of the study is GINI, which represents the income inequality of the developing country. Therefore, the interconnection of the variable GINI with the other variables is investigated through the correlation analysis technique. The results show that GINI has a significant association with all the other variables: the log of education expenditure (LEE), educational attainment of females, and overall educational attainment. The LEE is determined to have a significant correlation based on the p-value of 0.05. The coefficient value is computed as 0.3494, which suggests a positive correlation with GINI. This implies that an increase in educational expenditure leads to an increase in income inequality in developing countries.

Table 3. Correlation analysis.

\begin{tabular}{l|c|c|c|c}
\hline Variable & GINI & LEE & $\begin{array}{c}\text { Educational Attainment } \\
\text { (Female) }\end{array}$ & $\begin{array}{c}\text { Educational } \\
\text { attainment }\end{array}$ \\
\hline GINI & 1 & & & \\
\hline LEE & $0.349^{*}$ & 1 & & \\
\hline $\begin{array}{l}\text { Educational attainment } \\
\text { (Female) }\end{array}$ & $-0.173^{*}$ & -0.093 & 1 & 1 \\
\hline Educational attainment & $-0.277^{*}$ & $-0.238^{*}$ & $0.615^{*}$ & \\
\hline Note: Significance at $5 \%(0.05)$. &
\end{tabular}

Furthermore, female educational attainment is found to be negatively correlated with the GINI coefficient as the value of the coefficient is computed as -0.1732. The strength of the association is low as it is below 0.4 and above 0 . The results imply that educational attainment among females decreases the GINI by -0.1732 units. Lastly, the overall educational attainment is also negatively correlated with the GINI coefficient as the value is computed as -0.2768. As the coefficient value is below 0.4, it suggests that educational attainment has a low and negative correlation with GINI.

\subsection{Variance Inflation Factor (VIF) Test}

The multicollinearity among the constructs has also been checked using the VIF test. The rule of thumb of the VIF is that the values should be lower than five, which means there are no multicollinearity issues among the variables. The results show that the VIF values are lower than five, so there are no multicollinearity issues among the variables. Table 4 shows the VIF results.

Table 4. Variance inflation factor.

\begin{tabular}{c|c|c}
\hline Variables & VIF & $\mathbf{1} / \mathbf{V I F}$ \\
\hline $\mathrm{EE}$ & 3.342 & 0.299 \\
\hline EAF & 2.432 & 0.411 \\
\hline EA & 2.887 & 0.346 \\
\hline Mean VIF & 2.887 & $\cdot$ \\
\hline
\end{tabular}




\subsection{Hausman, Heteroscedasticity and Autocorrelation Assessment}

Table 5 provides the results of the preliminary testing of the regression analysis, for the purpose of determining which regression technique is most suitable to the provided data. The first test conducted is the Hausman test, which helps to determine whether the random effect or fixed-effect model is more relevant in the study based on the OLS regression. The null hypothesis of the Hausman test is that the random effect model is relevant for the OLS regression (Olanrewaju, Olubusoye, Adenikinju, \& Akintande, 2019; Purba \& Bimantara, 2020). The p-value is computed as 0.0023 , which is less than 0.05 ; therefore, the null hypothesis is rejected and the FEM is deemed more relevant. However, before finalizing the OLS regression, it is critical to examine the autocorrelation and heteroscedasticity issues in the dataset. The autocorrelation is evaluated using the Woolridge test, where the null hypothesis is that autocorrelation is absent (Kramer, Schorr, Doluschitz, \& Lips, 2019; Torres-Barreto, 2018). The p-value of the Woolridge test is computed as 0.214, which is above 0.05; therefore, the null hypothesis is accepted and there is no autocorrelation issue. The heteroscedasticity is examined through the modified Wald test, where the null hypothesis is that heteroscedasticity is an issue in the dataset (Khan et al., 2018; Sarkodie, Owusu, \& Leirvik, 2020). The results of the modified Wald test reveal a pvalue of 0.000 , which is below 0.05 ; therefore, the null hypothesis is rejected and there is an issue of heteroscedasticity. Due to the heteroscedasticity in the data, the use of the OLS regression technique is not appropriate.

Table 5. Hausman test, modified Wald test, and Woolridge test.

\begin{tabular}{l|c|c}
\hline Variables & Chi-square & P-value \\
\hline Hausman Test & 3.37 & 0.002 \\
\hline Modified Wald Test & 567.040 & 0.000 \\
\hline Woolridge Test & 0.214 & 0.214 \\
\hline
\end{tabular}

\subsection{Fixed Effect and Robust Standard Error Regression Analysis}

As indicated by the studies of Akpan and Moffat (2018) and Gopinath, Krishnamurthy, and Sathian (2018), the FEM technique can be used to resolve issues of autocorrelation and heteroscedasticity. Hence, the FEM analysis technique is undertaken to address the heteroscedasticity observed in the preliminary testing. Table 4 presents the FEM results, where the components of education are examined against the GINI coefficient. This enables a determination to be made whether educational mismanagement influences the income inequality of developing countries. As the results in Table 6 demonstrate, the probability value is computed as 0.000 , which indicates that the FEM is significant and thus has provided reliable results. Regarding the variables, it shows that the variables LEE, educational attainment of females, and overall educational attainment all have a significant effect on the GINI coefficient of the developing countries, based on p-values that are $<0.01$. Concerning LEE and educational attainment, these have been shown to positively influence GINI as the coefficient values are computed as 0.723 and 0.102 , respectively. Hence, a single unit change of LEE and educational attainment would result in an increase in the income inequality of developing countries by 0.723 and 0.102 units, respectively. This implies that high levels of expenditure on education and overall educational attainment negatively affect the developing country's income equality. On the other hand, the educational attainment of females is shown to have a negative effect as the coefficient value is computed as -0.149. This shows that an increase in the educational attainment of females has a positive effect on income equality as it leads to a reduction in inequality. The results imply that the educational attainment of females in developing countries can help to reduce the level of income inequality.

Table 6. Fixed effect analysis.

\begin{tabular}{l|c|c|c|c}
\hline GINI & Coef. & Std. Err. & $\mathbf{z}$ & $\mathbf{P}>|\mathbf{z}|$ \\
\hline LEE & $0.723^{* * *}$ & 0.095 & 7.590 & 0.000 \\
\hline EAF & $-0.149^{* * *}$ & 0.047 & -3.180 & 0.001 \\
\hline EA & $0.102^{* * *}$ & 0.018 & 5.580 & 0.000 \\
\hline cons & 23.467 & 2.467 & 9.510 & 0.000 \\
\hline Prob $>$ F & 0.000 & & & \\
\hline Note: *** Significance at 1\% (0.01).
\end{tabular}

Table 7. Robust standard error.

\begin{tabular}{l|c|c|c|c}
\hline GINI & Beta & S.D. & $\mathbf{t}$ & P>t \\
\hline LEE & 0.427 & 0.089 & 4.780 & 0.001 \\
\hline EAF & -0.044 & 0.009 & -4.780 & 0.001 \\
\hline EA & 0.135 & 0.042 & 3.214 & 0.016 \\
\hline - cons & 26.040 & 1.069 & 24.360 & 0.000 \\
\hline R-squared & 0.541 & Number of obs. & \multicolumn{3}{|c}{200} \\
\hline
\end{tabular}

Finally, the robust standard error is run to evaluate the nexus among the variables. The findings show that 
education expenditure and education attainment have a positive association with the GINI index, while education attainment in females is negatively associated with the GINI index. In addition, 54.1 percent of variations in the GINI index are due to the predictors used in the study. These nexuses are illustrated in Table 7 .

4.6. Granger Causality

Finally, the Granger causality test exposed the unidirectional association between EE and GINI and between EAF and GINI. In addition, the results revealed no relationships among EG and NREA and GINI. These results are listed in Table 8 .

\begin{tabular}{|c|c|c|c|}
\hline Null Hypothesis & F-Statistic & Prob & Decision \\
\hline EE does not Granger Cause GINI & 3.04 & 0.01 & \multirow{2}{*}{ Unidirectional } \\
\hline GINI does not Granger Cause EE & 0.60 & 0.69 & \\
\hline EAF does not Granger Cause GINI & 4.18 & 0.01 & \multirow{2}{*}{ Unidirectional } \\
\hline GINI does not Granger Cause EAF & 0.04 & 0.46 & \\
\hline EA does not Granger Cause GINI & 1.35 & 0.42 & \multirow{2}{*}{ No } \\
\hline GINI does not Granger Cause EA & 1.52 & 0.22 & \\
\hline
\end{tabular}

\section{Discussion}

Educational mismatch - the situation where a worker's education does not meet the requirements of a certain job description - remains a significant issue across the globe. High levels of educational mismatch have resulted in income inequality in certain countries. However, there have only been limited studies on the phenomenon in developing countries; therefore, this study has investigated educational mismatch and income inequality in developing countries. As indicated by the results of Khan (2019) and Chua and Chun (2016), enrolment rates in educational institutions have increased drastically in developing countries. However, educational mismatch is a significant issue in developing countries, where the qualifications of many employees fail to match those required by the job. Battu and Bender (2020) have demonstrated that such mismatches tend to have negative consequences for productivity and social welfare. Therefore, this study has sought to provide evidence that can support developing countries in addressing the issue of educational mismatch and thus reduce income inequality.

Data was gathered from 10 developing countries for the period 2001-2020, a twenty-year time frame. The variables used in the study to represent the educational mismatch are educational expenditure, educational attainment among females, and overall educational attainment. The variable representing income inequality was the GINI coefficient. The statistical analysis was conducted using Stata software, where the main methods included preliminary testing and regression. The preliminary testing of the dataset indicated a degree of heteroscedasticity. Therefore, the OLS regression technique could not be applied to the dataset. Hence, the GLS regression analysis technique was applied to address the heteroscedasticity. In terms of descriptive statistics, the mean value of the GINI coefficient for the ten developing countries was computed as 39.22\%, which, since it is between 30 and $40 \%$, indicates an adequate level of income equality in the country. The main findings of the GLS regression demonstrated that educational expenditure and overall educational attainment are responsible for income inequality. On the other hand, the educational attainment of females was shown to have a negative effect on the GINI coefficient, indicating that an increase in educational attainment among females generally leads to the reduction of income inequality in developing countries. The results thus suggest that overeducation tends to have an undesirable effect on economic growth. Moreover, workers who are vertically mismatched, including both overeducated and undereducated workers, tend to earn considerably less than well-matched employees (Maier, 2015). Furthermore, overeducated workers might feel dissatisfied with their work, resulting in counterproductive behaviors, such as higher rates of absenteeism and increased turnover rates, which are undesirable from the perspective of business growth (Battu \& Bender, 2020).

\subsection{Conclusion}

Education mismatch in developing countries has led to increased levels of income inequality. Hence, this research has aimed to contribute to a reduction in the level of educational mismatch by providing relevant findings that can help to increase income equality in developing countries. The study has investigated the influence of educational mismatch on income inequality in developing countries. The research made use of data from 10 developing countries over a twenty-year period (2001-2020). Statistical analysis was performed on the dataset using Stata, where the main variable representing income inequality was the GINI coefficient, and the educational mismatch was assessed through educational attainment, educational attainment of females, and educational expenditure. The results of the regression analysis revealed that educational attainment and educational expenditure have a positive influence on the GINI coefficient, indicating that the two factors are responsible for increasing the educational mismatch in the developing country. On the other hand, the findings also revealed that the educational attainment of females has a negative effect on the GINI coefficient, indicating 
that high levels of educational attainment among females can contribute to improved rates of income equality in developing countries.

\subsection{Implications of the Study}

The study results revealed that educational attainment among females has a significant and negative influence on the GINI coefficient. This suggests that an increase in educational attainment among females leads to improved income equality in developing countries. This has implications for the policymakers and governments of developing countries. In developing countries, the authorities should take steps to increase the level of education among females to improve their country's income equality. Governments can promote education among females by initiating campaigns and offering free education to the poor; the resulting increase in the female education attainment level will lead to a reduction in educational mismatch. Furthermore, improving female educational attainment in developing countries can contribute to income equality.

\subsection{Limitations and Future Directions}

This study was subject to several limitations. The major limitation was the sample size, as only ten developing countries were investigated, while the selected time frame was 20 years (2001-2020). Another limitation was that it only investigated developing countries, and developed countries were omitted from the study. Furthermore, the study only utilized a quantitative approach, whereas a qualitative methodology would also be applicable to the research topic to gain more relevant information. Based on these limitations, future research should increase the number of developing countries in the dataset to improve the reliability and validity of the results. Future researchers might also incorporate data from developed countries to allow further comparisons to be made regarding income inequality.

\section{References}

Akpan, E. A., \& Moffat, I. U. (2018). Modeling the autocorrelated errors in time series regression: A generalized least squares approach. Journal of Advances in Mathematics and Computer Science, 26(4), 1-15.

Andersson, J., \& Berger, T. (2016). Elites and the expansion of education in 19th-century Sweden (No. 149). Lund University, Department of Economic History.

Arshed, N., Hassan, M. S., \& Aziz, O. (2020). Does income inequality lead to education inequality? UMT Education Revierw, 3(1), 45-68.Available at: https://doi.org/10.32350/uer.31.03.

Battu, H., \& Bender, K. (2020). Educational mismatch in developing countries: A review of the existing evidence. The Economics of Education, 269-289.Available at: https://doi.org/10.1016/B978-0-12-815391-8.00020-3.

Bender, K. A., \& Roche, K. (2013). Educational mismatch and self-employment. Economics of Education Revier, 34, 8595.Available at: https://doi.org/10.1016/j.econedurev.2013.01.010.

Bourn, D. (2018). Globalisation, education and skills Understanding global skills for 21 st century professions (pp. 17-35). Cham: Springer.

Budría, S., \& Moro-Egido, A. I. (2008). Education, educational mismatch, and wage inequality: Evidence for Spain. Economics of Education Review, 27(3), 332-341.Available at: https://doi.org/10.1016/j.econedurev.2006.10.005.

Chin, V., Ioannidis, J. P., Tanner, M. A., \& Cripps, S. (2021). Effect estimates of COVID-19 non-pharmaceutical interventions are non-robust and highly model-dependent. Journal of Clinical Epidemiology, 136, 96-132.Available at: https://doi.org/10.1016/j.jclinepi.2021.03.014.

Chua, K., \& Chun, N. (2016). In search of a better match: Qualification mismatches in developing Asia. Asian Development Bank Economics Working Paper Series No. 476.

EERA. (2016). Testing on the theory of education mismatch: Evidence from PIAAC for twenty countries. Retrieved from: https://www.eera-ecer.de/ecer-programmes/conference/21/contribution/37228/. [Accessed 26th August $2021]$.

Gomathi, C., \& Rajamani, V. (2018). Skill-based education through fuzzy knowledge modeling for e-learning. Computer Applications in Engineering Education, 26(2), 393-404.Available at: https://doi.org/10.1002/cae.21892.

Gopinath, K., Krishnamurthy, V., \& Sathian, K. (2018). Accounting for non-Gaussian sources of spatial correlation in parametric functional magnetic resonance imaging paradigms I: Revisiting cluster-based inferences. Brain Connectivity, 8(1), 1-9.Available at: https://doi.org/10.1089/brain.2017.0521.

Guetterman, T. C. (2019). Basics of statistics for primary care research. Family Medicine and Community Health, 7(2), 60-67.

Kaur, P., Stoltzfus, J., \& Yellapu, V. (2018). Descriptive statistics. International Journal of Academic Medicine, 4(1), 60-60.

Kenway, J., \& Fahey, J. (2014). Staying ahead of the game: The globalising practices of elite schools. Globalisation, Societies and Education, 12(2), 177-195.Available at: https://doi.org/10.1080/14767724.2014.890885.

Khan, B. M. (2019). Education occupation mismatch in developing countries. Germany: University Library of Munich.

Khan, S. A. R., Zhang, Y., Anees, M., Golpîra, H., Lahmar, A., \& Qianli, D. (2018). Green supply chain management, economic growth and environment: A GMM based evidence. Journal of Cleaner Production, 185, 588-599.Available at: https://doi.org/10.1016/j.jclepro.2018.02.226.

Korpi, T., \& Tåhlin, M. (2009). Educational mismatch, wages, and wage growth: Overeducation in Sweden, $1974-2000$. Labour Economics, 16(2), 183-193.Available at: https://doi.org/10.1016/j.labeco.2008.08.004.

Kramer, B., Schorr, A., Doluschitz, R., \& Lips, M. (2019). Short and medium-term impact of dairy barn investment on profitability and herd size in Switzerland. Agricultural Economics, 65(6), 270-277.Available at: https://doi.org/10.17221/170/2018-agricecon. 
Lindgren, B.-M., Lundman, B., \& Graneheim, U. H. (2020). Abstraction and interpretation during the qualitative content analysis process. International Journal of Nursing Studies, 108, 103632.Available at: https://doi.org/10.1016/j.ijnurstu.2020.103632.

Lu, Y., \& Li, X. (2021). Vertical education-occupation mismatch and wage inequality by race/ethnicity and nativity among highly educated US workers. Social Forces, 100(2), 706-737.Available at: https://doi.org/10.1093/sf/soaa145.

Mahmud, S. S., \& Akita, T. (2018). Urban and rural dimensions of the role of education in income inequality in Bangladesh. Review of Urban \& Regional Development Studies, 30(3), 169-183.Available at: https://doi.org/10.1111/rurd.12089.

Maier, M. F. (2015). Skill mismatch and wage inequality. Paper presented at the CEDEFOP/IZA Workshop on Skills and Skill Mismatch.

Mukhtyar, M., Saleem, K., \& Iqbal, Z. (2021). Higher education enrollment trend and job opportunities in Pakistan: A subjectbased comparison. Ilkogretim Online, 20(5), 15-24.

Nag, S., Snowling, M. J., \& Asfaha, Y. M. (2016). Classroom literacy practices in low-and middle-income countries: An interpretative synthesis of ethnographic studies. Oxford Review of Education, 42(1), 36-54.Available at: https://doi.org/10.1080/03054985.2015.1135115.

Olagbaju, O. O. (2014). Multilingual education in Nigeria: Policy, practice, challenges and solutions. Journal of Education and Practice, 5(6), 66-73.

Olanrewaju, B. T., Olubusoye, O. E., Adenikinju, A., \& Akintande, O. J. (2019). A panel data analysis of renewable energy consumption in Africa. Renewable Energy, 140, 668-679.Available at: https://doi.org/10.1016/j.renene.2019.02.061.

Ordine, P., \& Rose, G. (2017). Too many graduates? A matching theory of educational mismatch. Journal of Human Capital, 11(4), 423-446.Available at: https://doi.org/10.1086/694455.

Polozov, A., Popovich, A., \& Kraev, M. (2021). Football techniques and tactics statistics: Case study of wyscout analytical system. Theory and Practice of Physical Culture, 5, 62-65.

Purba, J. H. V., \& Bimantara, D. (2020). The influence of asset management on financial performance, with panel data analysis. Paper presented at the 2nd International Seminar on Business, Economics, Social Science and Technology (ISBEST 2019). Atlantis Press.

Pyzdek, T. (2021). Descriptive statistics the lean healthcare handbook (pp. 145-149). Cham: Springer.

Rohrbach-Schmidt, D., \& Tiemann, M. (2016). Educational (Mis) match and skill utilization in Germany: Assessing the role of worker and job characteristics. Journal for Labour Market Research, 49(2), 99-119.Available at: https://doi.org/10.1007/s12651-016-0198-9.

Sam, V. (2018). Impacts of educational mismatches in developing countries with a focus on Cambodia. Doctoral Dissertation, Grenoble Alpes University.

Santos, M. S. (2012). Education, educational mismatch, and wage inequality: Evidence for different european countries. Doctoral Dissertation.

Sarkodie, S. A., Owusu, P. A., \& Leirvik, T. (2020). Global effect of urban sprawl, industrialization, trade and economic development on carbon dioxide emissions. Environmental Research Letters, 15(3), 034049.Available at: https://doi.org/10.1088/1748-9326/ab7640.

Schmidt, J. P., Resnick, M., \& Ito, J. (2016). Creative learning and the future of work. Disrupting Unemployment, 147-155.

Sweetman, A., McDonald, J. T., \& Hawthorne, L. (2015). Occupational regulation and foreign qualification recognition: An overview. Canadian Public Policy, 41(Supplement 1), S1-S13.Available at: https://doi.org/10.3138/cpp.41.s 1.s 1.

Tang, R., \& Wang, G. (2021). Educational mismatch and income inequality. Economic Modelling, 100, 105-121.Available at: https://doi.org/10.1016/j.econmod.2021.105525.

Torres-Barreto, M. (2018). Product innovations and R\&D public funding: How to handle heteroscedasticity and autocorrelation. International Journal of Trade, Economics and Finance, 9(1), 20-24.Available at: https://doi.org/10.18178/ijtef.2018.9.1.582.

Watts, R. D., Bowles, D. C., Fisher, C., \& Li, I. W. (2021). The growth of Australian public health graduates and courses, 2001-2018: Implications for education and employment opportunities. Australian and New Zealand Journal of Public Health, 45(2), 95-100.Available at: https://doi.org/10.1111/1753-6405.13076.

Williams, I. (2010). Plato and education. The SAGE Handbook of Philosophy of Education, 69-84.

Wooldridge, J. M. (2010). Econometric analysis of cross section and panel data: MIT Press.

Zhu, C., Zhu, H., Xiong, H., Ma, C., Xie, F., Ding, P., \& Li, P. (2018). Person-job fit: Adapting the right talent for the right job with joint representation learning. ACM Transactions on Management Information Systems (TMIS), 9(3), 117.Available at: https://doi.org/10.1145/3234465. 